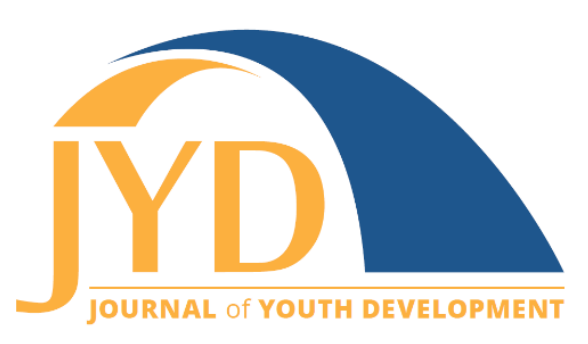

http://jyd.pitt.edu/ | Vol. 12 Issue 1 DOI 10.5195/jyd.2017.485 | ISSN 2325-4017 (online)

\title{
Will I be Able to Understand My Mentee? Examining the Potential Risk of the Dominant Culture Mentoring Marginalized Youth
}

\section{Jennifer Lindwall}

Portland State University

lindwall@pdx.edu

\begin{abstract}
Most people would agree they want to live in a world where every child has what he or she needs to thrive and grow into a healthy and productive adult. It is estimated that 5,000 mentoring programs serve 3,000,000 youth in the United States alone (DuBois, Portillo, Rhodes, Silverthorn, \& Valentine, 2011). In many of these programs, a majority of the mentors are matched with a mentee who comes from a culture and community they know very little about. Many of the youth development programs that were founded and implemented by people of the perceived dominant culture represent their values and cultural experience. To look more deeply into this, my primary research included seven one-on-one interviews with experienced youth workers, most who currently work at a community or site-based mentoring program. This article is a summary of their responses and reflections on the potential risks invovled in matching across culture and considers how we might work together to mitigate these risks for the youth we serve.
\end{abstract}

\section{Introduction}

"Will I be able to understand her?"

"I don't know what you mean."

"My mentee, will I be able to understand her? Last time I was a mentor and

had a little African American girl, sometimes when she talked I couldn't understand what she was saying."

This exchange between a potential mentor and a mentoring program staff was reported to me as a semi-typical interaction with prospective mentors. When the program staff sat silent after this statement, the women leaned forward and said, "You know," with a suggestive nod.

(cc) $\mathbf{E Y}$ New articles in this journal are licensed under a Creative Commons Attribution 4.0 License. This journal is published by the University Library System, University of Pittsburgh and is cosponsored by the University of Pittsburgh Press. The Journal of Youth Development is the official peer-reviewed publication of the National Association of Extension 4-H Agents and the National AfterSchool Association. 
Though it could seem harmless on the surface, this illustrates a chasm that exists between those seeking to be caring adult mentors and the young people whom programs are seeking to support in these relationships. It is estimated that 5,000 mentoring programs serve 3,000,000 youth in the United States alone (DuBois, Portillo, Rhodes, Silverthorn, and Valentine, 2011). In many of these programs, a majority of the mentors are matched with a mentee who comes from a culture and community they know very little about

\section{How Did We Get Here?}

Most people would agree they want to live in a world where every child has what he or she needs to thrive and grow into a healthy and productive adult. Opportunity gaps, poverty, unemployment, failing schools, homelessness, gun violence, and many other epidemics are indicators that as a global community, we are not collectively meeting the needs of each child. What is even more concerning is that many of these disparities can be drawn along lines of race and class. It isn't merely that not all kids are given what they need to be successful, but that consistently, kids of specific racial groups and socioeconomic classes are at a disadvantage. The Annie E. Casey Foundation's Race for Results policy report concluded "the odds are stacked against many children of color, who along with their families, disproportionately lack those resources. By nearly every measure in the Race for Results Index, [these] kids face some of the biggest obstacles on the pathway to opportunity" $(2014$, p. 2).

The concept of mentoring began in relationships occurring naturally in communities with known and trusted people such as neighbors, relatives, and coaches. However, within many communities numerous issues such as low graduation rates, low post-secondary completion rates, high unemployment, gun violence and a myriad of other things began to surface and people became increasingly concerned that kids were not finding the mentors they needed naturally. A Child Trends Research Brief stated, "Such [adult] involvement may be especially important for at-risk youth, that is, young people from poor, struggling, often single-parent families who live in neighborhoods that offer few positive outlets and a limited number of positive role models" (Jekielek, Moore, Hair, and Scarupa, 2002, p. 1).

This perceived community deficit of supportive, available adult mentors resulted in increased programmatic efforts to create these relationships, recruiting and training mentors to be matched up with youth in these communities (Hayashi and O'Donnell, n.d.). These programs utilize outside resources and people to form relationships and were by their very nature, formed out of a deficit ideology. Paul Gorski writes that, "We comply [with a deficit ideology] by attempting to redress the socioeconomic achievement gap by offering parenting classes and 
Will I Be Able to Understand My Mentee?

mentors to low-income families and students, measures that assume the chief problems to be what low-income communities lack" (2010, p. 6).

\section{My Stance and Intent}

I worked in the mentoring field for seven years. During that time, I had the chance to work with brilliant and committed people who were driven to be a part of the solution to the problems communities face. The reality remains that we live in a world that is inequitable and unjust. Those from what I will refer to as the "dominant culture" represent the race and class in power and are a part of the dominant culture of society-in the context of my work and research, this refers to middle-class and upper-class European Americans. These individuals often make up the majority of youth-serving organization staff and volunteers. Many youth-serving organizations target youth who are not in the dominant culture, but rather are part of minority groups which are often the target of discrimination and inequitable practices by institutions. I will refer to these groups as marginalized cultures or groups throughout this article.

The impact of history on how these groups perceive support and assistance from institutions and organizations that are outside their communities cannot be overlooked. Therefore, the creation and implementation of mentoring programs for people within marginalized communities by those from outside these communities pose a significant problem. Slavery, forcible removal of American Indians from their land, Jim Crow laws and discriminatory immigration policies have played a major role in shaping the life trajectories for tens of millions of Americans. American history is littered with an incalculable number of local, state and federal policies - as well as business practices - that set up racial barriers negatively affecting children of color today (The Annie E. Casey Foundation, 2014).

Community perception of outside support combined with an outsider's limited ability to understand the community's unique culture and experiences creates a barrier we must further examine. In this article, I will seek to provide sufficient evidence that mentoring relationships in which an individual from the dominate culture is mentoring a young person from a marginalized culture or population may negatively impact the young person, specifically in regard to their racial, ethnic, and cultural identity development.

This purpose of this article is not to critique or diminish the work being done in the field by thousands of caring and committed practitioners from the dominant culture, nor to prove that a person from outside a community cannot effectively support and empower those from in a marginalized group. As a white, middle class woman and lifelong member of the dominant 
Will I Be Able to Understand My Mentee?

culture I believe that we all have a significant role in addressing injustice and inequity where it exists, even in communities where we might be considered outsiders. I have the utmost respect for my colleagues who are committed to supporting young people and have opened themselves up to significant amounts of personal learning and growth, even in the midst of their own innate privilege. I am also fully aware that my ability to speak on this subject is impacted by my own place of power in our society and that my ability to ask provocative questions comes with less significant risk, in part because of the privilege afforded to me by my race and class.

My hope is to further a conversation about how these dynamics impact young people within marginalized communities and call for greater examination of how we are designing and implementing mentoring programs so that we can ensure that all kids have what they need to grow up healthy and whole.

\section{Mentoring as an Effective Youth Development Strategy}

There has been a significant amount of research done in the mentoring field to assess the effectiveness of mentoring programs. It is widely accepted that mentoring is a valuable youth development strategy and provides needed support to young people (DuBois, Portillo, Rhodes, Silverthorn, and Valentine, 2011). Many mentoring programs, even when designed and implemented by outsiders, have seen significant positive youth outcomes in a wide range of things.

In addition, the viewpoint that race, class and privilege still pose significant issues in our society is not shared by all people. The election of the first black U.S. president in 2008 fueled the belief held by many that we live in a post-racial society. A commentator on CNN said that night, "The politics of racial grievance die today," and another said, "We don't take excuses from anybody who says the deck is stacked, I can't do anything, there is so much [injustice] built into this or that." The claim that in the present day certain racial or socioeconomic groups do not have access to the resources that others do is not accepted by everyone. We live in a democratic nation where many accept that we can all drink from the same drinking fountains, attend the same schools, work for the same organizations, and meet our personal goals if we set our minds to it.

There are several public examples of people who were born into very difficult circumstances, living in impoverished communities, but who, with hard work and determination, were able to achieve their wildest dreams and be extremely successful by society's standards. Their stories of achieving the American Dream often involve a mentor from outside their community who 
gave them the leg up they needed to get out of poverty. One might think struggling communities need successful outsiders to come in and provide assistance and support so they are able to break through barriers and succeed. Isn't giving these kids the opportunity to be with people from the dominant culture exactly what they need to understand how to reach their goals in the midst of a nation dominated by middle-class, European American values?

Furthermore, there have been large-scale attempts to recruit mentors from within these marginalized communities but without success. This is especially true for black male mentors. "There is a national crisis for African American male youth seeking mentors because of the challenges involving recruitment and retention of adult African American mentors" (Miller, 2008, p. 4). So, some might say, if we focus on having mentors who are culturally congruent or come from within these communities, we wouldn't have enough mentors for kids who need them. After all, kids are better off with a caring adult in their lives than none at all. And there is not conclusive research to show that cross-cultural matches are less successful than same-race or same-culture matches (Liang and West, 2006).

I would argue that though there is evidence that mentoring relationships are having an impact on kids, the above claims do not provide sufficient evidence that mentors from the dominant culture pose no risk of harming youth from marginalized cultures, most notably when we consider their identity development. The notion that all kids are better off with a caring adult, no matter their experience or background, is not consistent with research in the field. Numerous researchers have looked at the harm done in relationships and concluded that mentoring relationships can do more harm than good in certain situations (Darling, Bogat, Cavell, Murphy, and Sanchez, 2006). Because mentoring relationships can be so formational in the development of a young person, the right match at the right time is crucial. And when we consider youth outcomes, we must recognize that success in one desired outcome, such as school attendance or post-secondary completion, does not negate potential harm in other areas. To broaden our perspective, we must ask ourselves difficult questions about how we best support young people in their continued growth and ensure they have the opportunity to explore their own identity in healthy, supportive relationships.

\section{My Approach to Gathering Data}

My primary research included seven one-on-one interviews with experienced youth workers, most who currently work at a community or site-based mentoring program. The programs vary in structure and focus on things such as health and wellness, academic success and leadership skill development. Three of the seven individuals run culturally specific programs requiring 
cultural congruency between mentors and students. The interviews lasted 60-90 minutes and were qualitative in nature. In addition, I conducted four focus groups with youth workers in Minneapolis totaling 65 people. The groups lasted only 20-30 minutes each and approximately 25 group members participated verbally. These individuals work with youth in a variety of settings such as schools, after-school programs, and community centers. Lastly, I conducted two focus groups with a total of 12 young people, all who were African American adolescent males ranging in age from 17-19. I relied most heavily on the one-on-one interviews as they were the most in-depth and provided more opportunities for clarification and in-depth explanations.

Though I will broadly use the term "marginalized cultures," it should be noted that a majority of my conversations focused on those within black communities. There was also feedback from people representing other racial or ethnic backgrounds including Latino, Asian, American Indian, and biracial. I recognize these groups cannot easily be lumped into one broader category when so much of their cultural identities and experiences have been so different. However, I rely on the themes that were consistent throughout my conversations and I will do my best to avoid making sweeping generalizations regarding whole groups from a perspective held by an individual.

\section{If You Can See It, You Can be It}

In my interview with David Wilmes, interim executive director at St Paul Youth Services, he said "Racial identity tends to be built on concrete examples." In other words, young people must have examples of people to look up to who look like them and have similar life experience, in order to imagine future possibilities for themselves. David told a story of one of his African American staff who grew up in a black community in New Orleans. "Everyone around him was black; all of his teachers were black, his dentist, his doctor. He told me 'I had all kinds of different identity options for what it means to be black. Then I came to Minnesota; all the teachers are white, all the doctors are white.' A black kid growing up on the east side of St. Paul, who is trying to figure out what it means to be an African American male, is not being exposed to the identity options that this staff had in New Orleans."

In his book, Countering the Conspiracy to Destroy Black Boys, Jawanza Kunjufu (1985) concluded that a majority of African American males can spend an entire career in the public schools and have very little interaction with an African American male teacher, counselor, or administrator. It is estimated that $84 \%$ of educators in the United States are white (Stockslager, 2013). In almost all of my seven interviews, my two student focus groups, and in three of the 
Will I Be Able to Understand My Mentee?

four youth worker focus groups, it was referenced that young people of color do not see people who look like them in positions of power and authority on a regular basis. One youth worker said, "In so many cases, in the justice system and in schools and outside of social places, our children of color are surrounded by white people and not by professionals that look like them."

Another African American youth worker spoke of her own life:

Growing up I had strong people who looked like me and who affirmed me in my race and affirmed me in my culture. Because I was affirmed early, it was easier for me to understand different facets of that as I grew older. How else do you define who you are if you don't have those people around you?

This leads to the question, should all kids from marginalized cultures be in a culturally congruent mentor match? I asked each group and individual if this was their preference and their reason behind their response. In almost every interview, people replied that in most cases, same-race matches for kids of color are preferred, for a variety of reasons, but the most frequently mentioned reason was so kids could have a concrete example of a person who looked like them in a position of power and could help them navigate the unique challenges that many kids of color face. In my interview with Neda Kellog, founder of Project Diva, she said,

We are trying to build up kids of color to be able to sustain themselves and bring themselves back; we are trying to build a community. Who can better build than those who understand the community? [Black people] don't need to go and build the white community, you have all that situated; you have your doctors, your bankers. You can go to each other and never touch a black person [in Minnesota]. We don't. Who can better teach them than their own people?

When I asked the youth this question, some said they were open to a mentor of any race as "long as he was respectable," while a few threw out that if they could pick, they would want a black mentor. In addition, several youth who responded specified that they would want a mentor who had a good understanding of their background and had overcome some challenges in life so they could relate to their life and experiences.

Many youth workers wanted same-race matches to support them as they learn to navigate a world where the color of their skin plays a significant role in how people see and interact with them. The reality of racism in the world requires much reflection and exploration with someone 
who understands it, preferably firsthand. When I interviewed adults of color, each one stated how acutely aware of their race they were at all times. One said, "I am constantly on high alert and aware of my race and the perception others have of me because I am black. I live with this every moment of every day and so do the black young men I work with." I heard stories of being followed around in stores, pulled over without reason, and targeted in various situations simply because of skin color.

There were some key considerations that people said must be looked at to determine the best type of cultural match for a young person. There was significant consensus that a young person's ability to benefit from a cross-race match was directly tied to the number of caring and supportive adults they had in their life that looked like them. One said that he wouldn't match up a "highly vulnerable" African American boy with a white mentor but said that if a young black man had a couple black male role models in his community, then being paired up with a white mentor could benefit him because it would give him a chance to see a different perspective. Others suggested that sometimes background and experience trumps race, so an African American man who grew up in an affluent family in a suburb might be less successful supporting a kid than a white male who grew up in north Minneapolis with a single mom.

Though we can't conclude that all young people of color are better off in same-race matches, some key factors need to be considered before making a mentoring match. Presently, in many of the mentoring programs in these communities, these factors are not assessed prior to the match and are not factors in the matching process. Healthy racial, cultural, and ethnic identity development is crucial for young people and requires greater access to concrete identity examples for kids from marginalized groups. We must consider the possible risk of placing an additional person of the dominant culture in a structured relationship where there is an innate power dynamic between mentor and mentee and consider how this might inhibit the healthy development of their identity. Though there is significant complexity involved in taking race, class, and ethnicity into account when making mentoring matches, these youth and youth worker perspectives further reveal the need for intentional, individualized efforts.

\section{The Assembly Line}

"Mentoring programs are another stop on the assembly line to rid the world of blackness and make everyone white." This statement, made by an African American youth worker I interviewed, is extremely alarming and should raise serious concern. As someone from the perceived dominant culture, the loud and clear message that there is only one right way to 


\section{Will I Be Able to Understand My Mentee?}

speak, act, dress, and behave goes unnoticed to me many days because it aligns with my personal cultural experience.

This is not the case for many individuals from marginalized cultures, who are consistently confronted with a status quo that deems their own cultural heritage and values inferior to another. Nathan Palmer (2013) writes that white supremacy is an ideology which encourages us to value white people, white culture, and everything associated with whiteness above the people, culture, and everything associated with people of color. We see this ideology in action everywhere, because the dominant culture cannot help but perpetuate a culture in which the values and attributes of white culture are seen as greater than others. In his book, Brainwashed: Challenging the Myth of Black Inferiority, Tom Burrell stated that "The marketing of black inferiority and white superiority as building blocks for the founding of America is a chick that has finally come home to roost" (2010, p. 26). Many people of color are constantly subjected, often subconsciously, to societal messages that elevate the dominant culture's values and cultural identity, while dismissing their own as ineffective, "less than," or nonsensical.

We talk often about wanting kids to be "successful." Even in the context of this article, I found myself wanting to use the word repeatedly saying things like, "The goal is successful kids" and "We all want kids to succeed." But what does this mean and how do we define success? Is success a series of life events or accomplishments? Is it a job title or an income bracket? I fear that our society's understanding of success for young people is oftentimes merely a reflection of the dominant culture's beliefs, values, and cultural experience. Instead of looking broadly at what is best for each individual, we end up focused on helping kids accomplish predetermined goals within a structure of society where success looks one specific way. This is painfully obvious in schools where kids from marginalized cultures are consistently shown the predetermined path for success. Elizabeth Stockslager (2013) states, "The groundwork for the structures to guarantee equality in the American education system stems from this case and reflects the country's dominant culture. Even with the Court's intention [in Brown vs. the Board of Education] to neutralize overt racism, our schools operate within a system that perpetuates the assumed dominance of White culture" (p. 3).

As a result, schools can be a confusing and unwelcoming learning environment for young people who are not members of the dominant culture and the impact is great. In my interviews and focus groups I heard stories of young people of color who were disciplined by hall monitors for walking in the hall in a group when a group of white students had just walked past and the hall monitor said nothing. Others told stories of low expectations for young students of color in 
Will I Be Able to Understand My Mentee?

classrooms everywhere and gave concrete examples, one woman saying "I have seen different standards in school. Any non-white kids are pushed into a special education class and given a lower standard of work much faster than the white kids." In her article, "Confronting the Racism of Low Expectations," Julie Landsman (2004) speaks of a white teacher who was overtly dumbing down questions for her students of color and upon being confronted was stunned. "She realized it was true and admitted, 'I just assumed you didn't know the answers and I didn't want to embarrass you."' Landsman goes on to say "This assumption-that black or Latino students could not possibly know the answer to deep or complex questions-is at the crux of the racism still embedded in many teachers' belief systems. This racism is so subtly expressed that students often cannot put into words what they clearly sense is wrong" (p. 29). Another Native youth worker echoed this, saying that Native kids know that teachers look at them differently, "These kids are not stupid. They are actually smarter than us and they know what is going on" (youth worker interview).

A young black man from the north Minneapolis told me of the numerous times he had been pulled over by police, he believed because of his race, for things such as biking in the middle of the street or driving with a light out. On one occasion, he was pulled over and after being given his license and registration back, which would usually end the interaction, the police proceeded to ask him questions about what he was doing, where he was going and then demanded a to search his car. I have lived in the same community as this young man for almost 10 years. I bike down the middle of the street ever day on my commute to work and have driven around for a full year with a taillight out, it strikes me that I have not been pulled over or questioned once for either of these things. This further illustrates that people are frequently targeted because of their cultural identity and are repeatedly reminded that they must either adapt to the dominant culture or continue to be targeted.

I would argue that our immobile and predetermined view of success has no place in the youth development field. Of course things such as high school graduation, college and career readiness, and lack of contact with the justice system are desirable outcomes for all young people. But thinking only of short term goals can inhibit us considering the greater goal of the healthy identity needed for a person's continued growth and sustained success in life and relationships.

Continually subjecting kids of marginalized cultures to relationships where their race and culture are not understood or validated by someone can perpetuate this sense of inferiority. Though most mentors would not make overtly racist comments, the damage occurs when a relationship 
perpetuates the assumption that there is a cultural identity that is "right" and "superior" and that all other groups must conform to it. As an example of this, in one interview I heard a story of a mentor who was recently matched with an African American 11-year-old girl. Right away, the mentor was very adamant about taking the young girl to her country club in a suburban community and emphasized that this was a priority. She said she was going "to teach her how to act, show her how to speak properly, and teach her how to look people in the eye." In this, we see an example of a well-meaning and caring adult putting this young girl's cultural identity development at risk by seeing her role as the one to show her mentee the "right way" to live. This sometimes subtle, yet damaging mindset mentors can bring into the relationship can have a very negative impact on their mentee's perception of their own race and culture.

Gayle Smaller, the founder and Executive Director of a culturally congruent mentoring program said in our interview that these mentoring relationships can "increase the racial inferiority complex of young boys of color. If I start to view the functionality and attributes of my mentor as characteristics of whiteness, this further pounds home the idea of racial inferiority." As a result, young people are left with even fewer tools to help them understand their identity and can respond in a couple different ways. First, Smaller pointed out that the youth can see their only shot at success is to become like their mentor, to assimilate into the dominant culture and abandon any personal sense of their ethnicity or racial identity out of fear that it will keep them from succeeding. Another youth worker pointed out that this can result in irreversible damage where a young person abandons their culture and ethnicity for "success" and then loses all connections with family and community members, no longer having a place to call "home."

An alternative reaction to the cultural abandonment that Smaller describes is to do the opposite: a young person may choose to reject all things that could be perceived as part of the dominant culture so as not to sell out or "become white" as people described it. This reaction, one youth worker said, leaves them with very few options, limiting their ability to set goals, because they often can see themselves only as "gang bangers or athletes." If we don't proceed carefully, a mentoring relationship has the potential to further perpetuate a young person's misunderstanding and misgivings about their culture, creating an environment where cultural abandonment or rejection of all acculturation seem like the only viable options.

Instead, we must cultivate in young people from marginalized groups a strong sense of self so they can choose how to integrate the different aspects of their own cultural and ethnic identities with that of the dominant culture into their lives and relationships. Neda Kellogg from Project Diva said, "It is the oppressor and the oppressed, you just make it work. You just do 
what you can to get to a point where you can determine how you assimilate." Learning to do this well takes guidance and support from someone who understands this delicate balance and how to complete this process without losing one's cultural heritage. In several conversations with individuals of color we discussed the importance of "being in the driver's seat" when it comes to acculturation. Smaller spoke of his own process of figuring out how to navigate the dominant culture, learning how to speak differently and act differently depending on where he was and who he was with. "As a black man, I constantly have to adapt what I say and how I say it depending on who I am with. If my Northside friends were here today and overheard us, they wouldn't even recognize my voice. Same if you found me with them on the Northside. The reason I am comfortable doing what I do is that I look at it with equality. I am purposely making adjustments not because I think my culture is inferior, but to move my life forward in the way I want to. I am taking the best of both and making the decisions for myself." When I asked him how and where he learned to do that, he talked of mentors, both black and white, who helped him in that process.

We must work to support young people on a journey of self-discovery, as they recognize their worth and potential, figure out what they want from life, and consider how they might go about reaching their goals. Writer and theologian Frederick Buechner once said, "Your vocation in life is where your greatest joy meets the world's greatest need." To me, this speaks of real success and our hope for each young person who grows up in this world.

If this becomes our shared vision, our strategies to provide mentoring relationships remain crucial but may differ for each individual. It cannot be seen as a one-size-fits-all approach that will yield similar results for each mentee. Adolescence holds many crucial steps along the path of true self-discovery and we know that healthy racial and ethnic identity development is central in healthy identity development, especially for those who find themselves in marginalized populations (Renn, 2012) . We cannot underestimate the possible significance of a mentor's role, either in supporting or inhibiting, this development in kids who are part of marginalized cultures.

\section{Mentors Navigating Issues of Race, Class, and Privilege}

In a recent coffee shop visit, I was reading Jawanza Kunjufu's book, Countering the Conspiracy to Destroy Black Boys. A man sitting nearby was struck by the title and began a conversation me, stating that he was well educated, progressive, open, and the parent of three successful children all of whom had completed doctorates. He went on to tell me of the numerous mentoring and tutoring positions he had held working with young black boys. Each time he 
used the words "African American" he would lean forward and whisper it, as if it was a secret or something we weren't supposed to say out loud. Some of his experience had been on the north side of Minneapolis, at a high school about five blocks from where I live. He said, after years living in [the suburbs], it was obvious that the Minneapolis Public Schools were a "total train wreck" and he suggested that we just "bulldoze most of the city of Minneapolis and start over." He also spoke of an African American boy he had mentored in his job last summer, whom the man sensed he had helped significantly. This boy had never been told about college and the man stated, "He wasn't going get it from anyone in his family or community so I had to be the one to tell him." He said that "these kids must enter the school system and incrementally succeed in the areas of academics, athletics, and personal leadership development, in that order, like my kids did, if they want to have a chance of making it."

I relate this conversation not to demonize this gentleman. He seemed well meaning, interested in my work, and I believe he really saw himself as a helpful and supportive adult for kids in the communities he worked in. But the questions must be asked: Did he state any of these viewpoints in his interviews for these positions? Did he state them to the kids? What type of training did he receive and was anyone monitoring his relationships with these young people? His bold assertion about the supremacy of his own cultural identity over those of others, indicates that there is much potential harm that could come from pairing him up with a young person who does not have a strong sense of his or her own racial, cultural, or ethnic identity.

Because of the complexity of these issues in these relationships, we must avoid matching up mentors who are not equipped to navigate and provide intentional space to discuss the dynamics at play. Many see mentor training as a key way to address this concern. However, we know program staff have limited time to train new mentors and within these training sessions must cover a lot of content including program rules, basic mentor requirements, mandatory reporting laws, and other important aspects regarding how to engage with youth effectively. There is evidence that many programs are incorporating training around cultural competency into these sessions, but it isn't enough to ensure mentors from the dominant culture are prepared. In fact, the training and reflection needed for a person to effectively navigate issues of race, class and privilege with a young person, far exceed what most programs are currently able to provide.

I talked with one program staff at a program where a majority of the pairs are white mentors from affluent communities matched with kids of color from urban communities; she said that cultural competency is not a significant part of training and hardly mentioned because they 
have so many other items to cover. Other programs said they do a very thorough job of covering this topic in their initial mentor training but often find it difficult to get their mentors to attend follow-up sessions, read materials, or report back on their experiences and reflections to ensure they are integrating what they learned into their mentoring relationship. It takes a highly skilled, trained, reflective and humble individual to do this effectively. We must proceed with caution, recognizing the damage that could be done if we match up a well-meaning adult with a vulnerable young person who is ill-equipped to navigate these topics in their mentoring relationship.

\section{Those are the Rules}

Many of the youth development programs that were founded and implemented by people of the perceived dominant culture represent their values and cultural experience. Some are mystified by the struggle to recruit mentors from marginalized communities and attribute it to lack of interest or availability. Yet in my interviews with youth workers, it was clear that the mentoring field as a whole is seen by many marginalized people as yet another institution that is designed by and for people who represent the dominant culture, requiring adaptation from those in marginalized cultures.

This is very relevant information when we consider that one of the main reasons we continually match young people up with those from outside their community is a perceived lack of mentors from within their neighborhoods and cultural groups. One program staff described the process of seeking volunteer opportunities as a black woman in an environment dominated by white culture as yet another place she has to adapt and adjust how she talks and looks and acts which requires so much of her energy already, it exhausted her to think about navigating it as a volunteer.

Some of the youth workers I talked to clearly articulated that some programs seem to require volunteers to talk and act in a certain way and that people of color don't want to have to adapt in those ways to prove they can be an effective mentor. Some pointed out crucial barriers to people volunteering as mentors including things like the screening process, time commitment, organizational culture, and other programmatic elements that discourage or disable mentors who are not part of the dominant culture from participating. We must take into consideration the systematic ways in which we may be excluding specific groups of people from being mentors, even unintentionally. 
When many think of desired mentor characteristics, things like good communication skills, timeliness, and a willingness to follow program rules often come to mind. On one hand, these things make sense. However, they are all based on one's personal definition of what these things mean, which is relative to a person's cultural experience. Elizabeth Stocklager states that some cultures "may also recognize or define values such as civility, kindness, and honesty differently from the dominant culture" (2013, p. 9).

When we define desired mentor characteristics looking through the lens of the dominant culture, we risk creating environments where people feel out of place, excluded, and forced to act out a specific cultural identity to appear competent. A young woman recently commented that in college she had her first black teacher and got one of her first A's ever, doing so well in the class that she even surprised herself. When I asked her why, she said "Because right when I saw my teacher, and she looked like me, I knew that I could just be myself. I didn't have to talk a certain way or pretend to be a certain thing to be legit." This young person is the kind of person we need as a mentor, but we must not create programs where she feels forced to "talk or act in a certain way" or we run this risk of her not being willing or able to participate.

In addition, many programs have rules that create barriers for involvement for some individuals. For example, many programs require mentors to have a driver's license and have their own car, excluding recent immigrants and others who are unable or unwilling to drive or own a vehicle from participating. Others do not allow mentors to have contact with their students outside of on-site supervised programming. One staff of color pointed out how culturally incongruent this policy in for his black families in Saint Paul who don't trust anyone that they cannot see outside of a school environment. Many programs require mentors to demonstrate a certain proficiency in writing through lengthy applications. These program rules were created with good reason and make sense in many cases. However, we must think about the possible community members we could miss if people have the impression they need to write or speak in a specific way to get into a program. I am not suggesting that we do away with applications or online communication, or that we don't ask a mentor to have a car, but if we aren't considering the possible exclusive nature of these rules and coming up with exceptions when needed, then we aren't moving towards increasing access to adults from within their cultural groups.

As an example of this dynamic, a program staff told me a story of a mentor of color working in her program. Her mentee had a cousin in need of a mentor and the women's husband was able and willing to step in and fulfill the role. The four of them met and hit it off; the couple was so excited about the opportunity to mentor side-by-side with these kids. The program staff was 
elated at the opportunity to match these two youth in culturally congruent matches. However, when the staff went to make the match official in the program, she ran into some barriers. First of all, the mentor didn't have a high school diploma, which was required by the program. Also, the program activities were very focused and the husband didn't sense these activities would be the best way to build trust with his mentee. In the end, the program decided that because he did not have the required characteristics or fit into the program structure, he would not to be allowed to mentor this young boy.

Another significant barrier for many people is the screening process which almost always includes a background check. Good screening keeps kids safe from harm and it is our job to ensure that we consider any and all pertinent information about someone's background before we put them into a relationship with youth. As a result, many programs have policies that exclude anyone with a criminal background of any kind from serving in their program. There is some good rationale in this. On the other hand we know there are inequities in the justice system's processes that disproportionately impact people of color. A recent local report concluded that in Minnesota young people of color are more than three times more likely than whites to be arrested for a delinquency offense. Black teens, in particular, are more than six times more likely to be arrested than their white counterparts (Swayze and Buskovick, 2012). As a result more adults of color find themselves with recorded offenses than those of the perceived dominant culture. This means that systematic inequities in the justice system makes it more difficult for certain individuals to mentor than their counterparts from the dominant culture.

If we are committed to the healthy identity development of young people, then we must work to create supportive mentoring matches where they can be validated, encouraged, and guided in their journey. We must ensure that the culture of mentoring programs, as well as the specific program practices and rules, are as inclusive as possible so that we don't risk the systematic exclusion of mentors from marginalized populations and limit the mentors available to the young people we seek to support.

\section{The Risk of Speaking Up}

In my interviews and focus groups, it struck me that there seem to be some limitations on the conversations about race, class and privilege. Several of the youth workers I interviewed expressed frustration at the lack of depth of these conversations and how infrequently they seemed to occur given the potential severity of the issues at hand. It appears to me that some practitioners of color don't feel comfortable saying what they truly think to the broader field, 
despite how strongly they feel about it, for fear of diminishing their credibility. Any time multiple members of a group feel unsafe to speak their truth we must take a closer look at the forces, voices, or pressures contributing to that perceived lack of safety.

To illustrate this reality, a few people I interviewed weren't comfortable being directly quoted about what they said. This seemed to be for fear of the impact it could have on their reputation and their work. It seemed some were carefully calculating what they said and how they said it, afraid that if they were too straightforward about their view of the impact of the perceived dominant culture mentoring youth from marginalized cultures, they might put their work at risk. Another was grateful that this article was moving forward because "If I said it, it would just be chalked up to 'angry black man syndrome." At least two others shared this sentiment regarding why they hesitated to bring these issues to the public sphere.

To me, this point might be the most important and was one of the most significant personal discoveries of this experience. This is my final appeal, even to those who would disagree with the claims in this article: that we create a broader and safer space to talk about this so that all voices can be heard and valued. Youth workers from marginalized communities are some of the best resources we have to learn and grow as a field. If these voices are not being elevated and given safe spaces to speak as candidly and truthfully as possible, we are missing out on the key information that we need to move forward and increase the effectiveness of our work.

\section{Where Do We Go from Here?}

My intent here has been to provide significant anecdotal evidence that mentoring relationships in which an individual from the dominant culture mentors a young person from a marginalized culture may negatively impact the young person, specifically in regard to their racial, ethnic, and cultural identity development. By exploring youth worker and youth perspectives on this topic, I hope to have called attention to the importance of considering this further as the field continues to deepen mentoring efforts and adapt mentoring strategies in our work with young people.

I would like to offer a few potential next steps as we move forward. First, we must do more research on these relationships, facilitate conversations where we can foster greater understanding of these dynamics, and seriously consider how our program practices could be putting young people from marginalized cultures at risk. I recognize this creates anxiety for the field because it challenges the infrastructure of many programs and creates uncertainty about 
Will I Be Able to Understand My Mentee?

how we best move ahead. Despite this, we cannot continue to build and sustain these practices without further consideration.

Second, programs must examine what is needed to best equip mentors to have conversations about race, culture, ethnicity and other related topics in their mentoring relationships. I believe that with an intentional ongoing dialogue and a commitment to incorporate new learnings and discoveries into program practices these programs can do much to help young people form healthy racial and cultural identities. There must be an acknowledgement of the cultural chasm, openness to dialogue, and a commitment to staying in the conversation, even when it is uncomfortable for those involved. As Gayle Smaller put it, "You can be white and be a good mentor to a young person of color. You just have to validate your mentee's race, teach them how to hold on to it, and help them navigate systems that are going to require them to behave in a specific way to be successful." This takes a program's willingness to continually learn and adapt screening, training, and ongoing support processes of their mentors.

Third, people of the dominant culture must be open to giving up power so that the view of those in marginalized groups can be elevated. This will require a willingness to listen with the intent to understand, instead of respond. As Paulo Freire said in his book, Pedagogy of the Oppressed, "The solution is not to integrate [the oppressed] into the structure of oppression, but to transform the structure so that they can become beings for themselves" (1993, p. 23). To do this well, those who currently hold the power, must lay it down and allow others to step in and share their beliefs, experiences and ideas for the benefit of all.

To close, I bring us back to a core question I asked earlier in this paper in regard to our greatest hope for young people. What do we dream for all children? We want kids to find where the world's greatest need intersects with their greatest passion. We want to provide the best group of supportive and caring adults possible to help them grow up knowing where they came from and who they can be in the world. To do this we must be willing to have difficult discussions about how best to support kids from marginalized cultures in mentoring relationships. Only then will we be able to use these relationships to create a world where every child has the opportunity to grow up healthy and whole.

\section{References}

Annie E. Casey Foundation. (2014). Race for results: Building a path to opportunity for all children. (Kids count policy report). Retrieved from http://www.aecf.org/resources/racefor-results 
Burrell, T. (2010). Brainwashed: Challenging the myth of black inferiority. New York: Smiley Books.

Darling, N., Bogat, A. G., Cavell, T. A., Murphy, S., \& Sanchez, B. (2006). Gender, ethnicity, development, and risk: Mentoring and the consideration of individual differences. Journal of Community Psychology, 34(6), 765-779. DOI: 10.1002/jcop.20128

DuBois, D. L., Portillo, N., Rhodes, J., Silverthorn, N., \& Valentine, J. C. (2011). How effective are mentoring programs for youth? A systematic assessment of the evidence. Psychological Science in the Public Interest, 12(2), 57-91. DOI: $10.1177 / 1529100611414806$

Freire, P. (1993). Pedagogy of the oppressed. New York: Continuum Books.

Gorski, P. (2010). Unlearning deficit ideology and the scornful gaze: Thoughts on authenticating the class discourse in education. Retrieved from EdChange website: http://www.edchange.org/publications/deficit-ideology-scornful-gaze.pdf

Hayashi, Y., \& O'Donnell, C. R. (n.d.). A review of mentoring studies and websites: A report for the Melissa Institute for the prevention and treatment of violence. Retrieved from Melissa Institute website: http://www.melissainstitute.org/documents/TMI_Mentoring_Report51-2.pd

Jekielek, S. M., Moore, K. A., Hair, E. C., \& Scarupa, H. (2002). Mentoring: A promising strategy for youth development. (Research Brief No. 2002-21). Retrieved from Child Trends website: http://www.childtrends.org/wp-content/uploads/2002/02/MentoringRB.pdf

Kunjufu, J. (1985). Countering the conspiracy to destroy black boys. Sauk Village, IL: African American Images.

Landsman, J. (2004). Confronting the racism of low expectations. Educational Leadership, closing the achievement gap. 62(3), 28-32. Retrieved from http://ipsdweb.ipsd.org/uploads/PDAC/Confronting_the_Racism_of_Low_Expectations.p df

Liang, B., \& West, J. (2006). Youth mentoring: Do race and ethnicity really matter? Research in Action Series, Issue 9. Retrieved from MENTOR/National Mentoring Partnership website: http://www.mentoring.org/downloads/mentoring_390.pdf 
Miller, D. (2008). Man up: Recruiting and retaining African American male mentors. (A report from the Urban Leadership Institute.) Retrieved from http://www.issuelab.org/resource/man_up_recruiting_and_retaining_african_american_ male_mentors

National Mentoring Working Group. (1991). Mentoring: Elements of effective practice. Washington DC: National Mentoring Partnership.

Palmer, N. (2013). White supremacy: Not just the Neo-Nazis. Retrieved from Sociology in Focus website: http://www.sociologyinfocus.com/2013/04/08/white-supremacy-not-just-neonazis

Renn, K. A. (2012). Creating and re-creating race: The emergence of racial identity as a critical element in psychological, sociological, and ecological perspectives on human development. In C. L. Wijeyesinghe \& B. W. Jackson, III (Eds.) New perspectives on racial identity development (pp. 11-32). New York, NY: New York University Press.

Stockslager, E. (2013). Supporting minority students through mentoring: Best practices for formal mentoring programs. (Master's thesis). Retrieved from: http://ecommons.luc.edu/cgi/viewcontent.cgi?article=2855\&context=luc_theses

Swayze, D., \& Buskovick, D. (2012). On the level: Disproportionate minority contact in Minnesota's juvenile justice system. St Paul, MN: Minnesota Department of Public Safety Office of Justice Programs. 